\title{
Modulation of a R245fa Supersonic Ejector By A Movable Needle: A Numerical Study
}

\author{
Charles P. Rand ${ }^{1}$, Sergio Croquer ${ }^{1}$, Michel Poirier ${ }^{2}$, Sébastien Poncet ${ }^{1}$ \\ ${ }^{1}$ Département de génie mécanique, Université de Sherbrooke, 2500 boulevard de l'Université, \\ Sherbrooke, QC J1K 2R1, Canada \\ Charles.Rand@usherbrooke.ca, Sergio.Croquer.Perez@usherbrooke.ca, Sebastien.Poncet@usherbrooke.ca \\ ${ }^{2}$ CanmetÉNERGIE-Varennes, Ressources naturelles Canada, 1615 boulevard Lionel-Boulet, Varennes, QC J3E 1P7, \\ Canada \\ Michel.Poirier@canada.ca
}

\begin{abstract}
The current study explores the performance of a variable geometry ejector (VGE) working with R245fa. The ejector is equipped with a needle that controls the primary nozzle throat area $\left(\mathrm{A}_{t}\right)$. The nozzle head exit position (NXP) is also adjustable. Three different primary nozzle throat area values are tested: $1.00 \mathrm{~A}_{\mathrm{t}}, 0.80 \mathrm{~A}_{\mathrm{t}}$, and $0.61 \mathrm{~A}_{\mathrm{t}}$. The performance curves of both CFD and experimental tests are compared. The k- $\omega$ SST shows good agreement with the experimental values. Changes to the shock train formation are also observed. The effect of the needle on the reduced primary mass flow rate is compared to a primary pressure reduction.
\end{abstract}

Keywords: Variable geometry ejector, needle, R245fa, experimental test bench, CFD

\section{Introduction}

The use of ejector as thermal vapour compressors (TVC's) in refrigeration systems has been extensively studied. Utilizing reject heat or heat generated from renewable sources such as geothermal or solar, to drive the ejector refrigeration system (ERS) significantly reduces the amount of electricity needed to provide cooling as the compressor is replaced by an ejector and a pump [1]. The reader may refer to Grazzini et al. [2] for a comprehensive review on ejectors in refrigeration technology. Experimental studies have focused on the use of steam [3], R134a [4], R245fa [5], and more recently, of low GWP refrigerants such as HFO/HCFO's [6]. Aidoun et al. [7] describe the use of single-phase ejectors in and outside of refrigeration systems. The ejector is comprised of two flows: a primary (motive) flow, which entrains a secondary flow. The thermal vapour compression happens through the transformation of kinetic energy into pressure in the diffuser. The entrainment ratio $(\omega)$, which is one of the main metrics to quantify the ejector performance, is defined as the secondary mass flow rate divided by the primary mass flow rate. It remains constant for a specific interval of ejector back pressure in the socalled double chocking regime [8]. Beyond this point of critical back pressure, the entrainment ratio decreases dramatically to subcritical or single chocking conditions and further increasing the back pressure may lead to back flow (negative entrainment ratio) [8]. Both the entrainment and compression ratios are largely influenced by the operating inlet conditions [8,9]. Traditional ERS are designed for a specific set of operating conditions and exhibit lower performance outside.

Numerical studies using Reynolds Averaged Navier-Stokes (RANS) closure are now common to capture the flow dynamics in ejectors. Bartosiewicz et al. [10] studied flow characteristics by focusing on the diagnosis of an air ejector. They found that the formation of a Mach disk near the primary nozzle led to secondary flow separation which reduced the entrainment ratio in turn. Sriveerakul et al. [11] studied the effect of the outlet pressure on the displacement of the chock train within the ejector and were able to establish, for fixed inlet conditions and by varying the outlet pressure, the critical choking conditions. Ruangtrakoon et al. [12] studied different primary nozzle configurations for a steam ejector. They investigated the influence of the area ratio (AR), which is the area of the constant area section (CAS) divided by the primary nozzle throat area. The entrainment ratio was found to decrease with the increase in primary nozzle throat diameter (from 1.4 to $2.6 \mathrm{~mm}$ ) at a fixed primary pressure and same mixing section diameter at the critical operating point. The combination of the lowest generator pressure and the highest primary nozzle throat diameter entrained the least amount of fluid. Gagan et al. [13] determined that k- $\varepsilon$ more closely predicted the flow characteristics, confirming the former results of Bartosiewicz et al. [10]. For R134a, Croquer et al. [14] compared the k- $\varepsilon$, k- $\varepsilon$ realizable, RNG k- $\varepsilon$ and shear stress transport (SST) k- $\omega$ SST closures. The k- $\omega$ SST with the low-Reynolds number correction best represented the oblique shocks, while providing similar 
results for the entrainment ratio compared to the k- $\varepsilon$ models. The use of the k- $\omega$ SST model developed by Menter [15] has been repeated by many authors for the CFD modelling of supersonic ejectors $[6,16]$.

Considering the limitations of using a fixed geometry ejector, different flow modulation techniques have been studied in order to control the ejector for variable power operation. The first type is the use of multiple ejectors in a parallel configuration. This option has mainly been used to increase the performance of R744 vapour compression refrigeration systems [17]. Smolka et al. [18] were one of the first to numerically validate the use of multiple ejectors in a parallel configuration (multi-ejector) for two-phase flows. The technology has since been applied in large and medium scale systems. In the case of single-phase vapour flow, Sokolov and Hershgal [19] suggested using two ejectors in a heat driven refrigeration cycle whereas the use of one ejector or the other is determined by a selector switch. The most recent option is the use of pulse width modulation (PWM) to match the refrigerant flow for the cooling need [20]. The last option is the use of a variable geometry ejector (VGE). Sun [21] studied the effect of the operating conditions on the ejector length and primary nozzle diameter. It was determined that variable geometry ejectors offered greater flexibility. The area ratio (AR) is the ratio between the CAS ( $\mathrm{A}_{\mathrm{CAS}}$ ) and the primary nozzle throat area $\left(\mathrm{A}_{t}\right)[22]$. A needle or spindle is used to regulate the primary mass flow rate. Varga et al. [23] numericaly simulated the use of a moveable spindle at the primary nozzle throat. The model lacked accuracy for predicting the secondary mass flow rate as the tests were done for low evaporator pressures even though the average reported error was $7.7 \%$ between experimental tests and CFD modeling [24]. They found that an optimal AR of 4.85 presented a $25 \%$ increase in entrainment ratio using steam as a motive fluid for fixed inlet and outlet conditions. More recently, Shazamanian et al. [25] did a numerical assessment of a movable needle in a heat driven refrigeration cycle used for desalination. The very limited results obtained agreed with the previous studies but lacked in-depth analysis. The current study goes further by properly exploring multiple data sets of both experimental and numerical results.

The main objective of this study is to determine the effect of the VGE within the ERS. By doing experimental tests, the potential impact of the needle specifically on the primary mass flow rate, the entrainment ratio and the critical compression ratio is explored. The study of the performance of the ejector within an EHRDC allows for a better understanding of the uses of waste heat and heat of renewable sources such as solar or geothermal. The generator temperature situated around $114^{\circ} \mathrm{C}$ is within the upper limit of waste heat reuse noting that the system could work at temperatures as low as $60^{\circ} \mathrm{C}$ using a different refrigerant. The objective of the RANS study is to identify any disturbances caused by the presence of the needle within the ejector. The numerical study also gives an inside look into the flow phenomena within the ejector.

\section{Numerical setup}

A two-dimensional axisymmetric and steady-state model has been built using the commercial software ANSYS Fluent 2020R1 for a single-phase supersonic ejector with R245fa as the working fluid.

\subsection{Geometrical modeling}

A needle (Figure 1) is used as a flow control device to modulate the primary throat area. A numerical benchmark is considered using the ejector described at Figure 2. The finite volume method is employed throughout the calculations. The geometry of the ejector studied is that of the one described in Figure 2 and all its dimensions are provided in Table 1. For the series of tests, three different needle positions resulting in primary nozzle throat area values of $1.00 \mathrm{~A}_{t}, 0.80 \mathrm{~A}_{t}$ and $0.61 \mathrm{~A}_{t}$ are considered. The tests are done in order to re-create the operating curves presented in subsection 3.1.

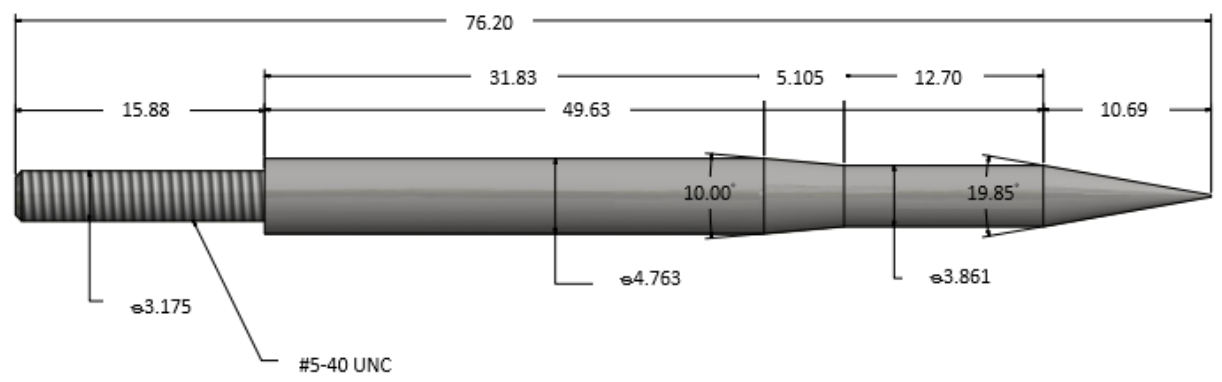

Figure 1: Needle geometry with relevant dimensions (mm). 


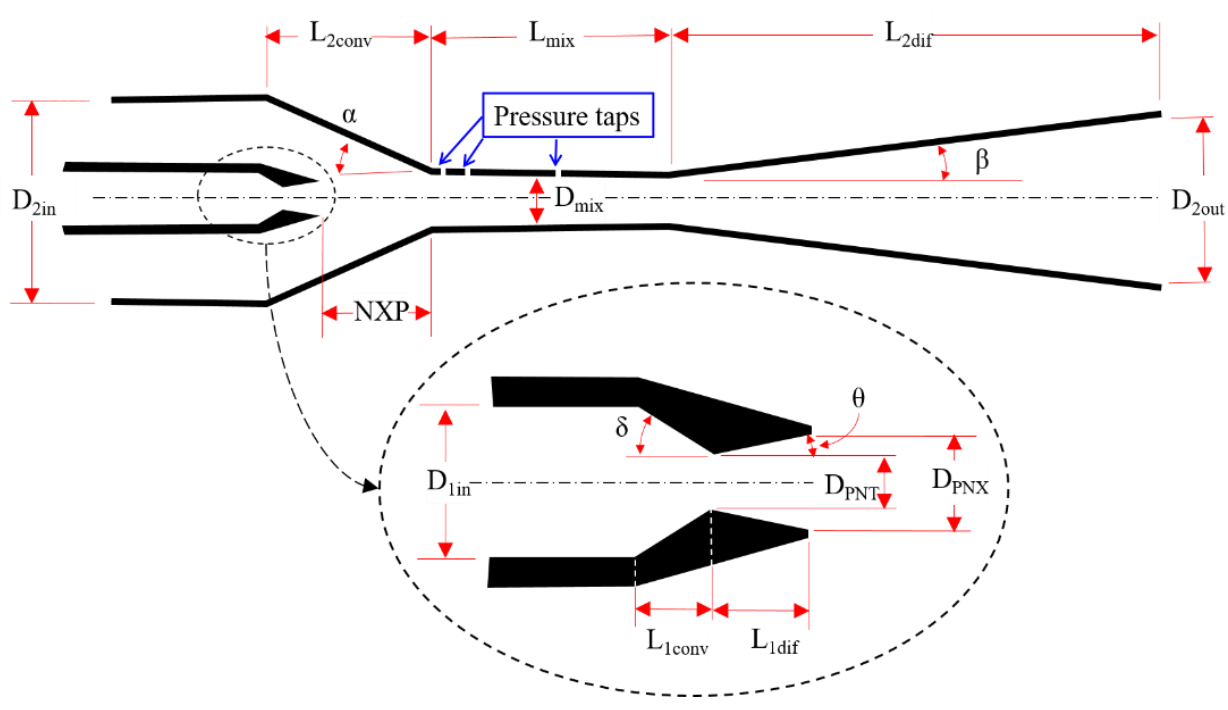

Figure 2: Ejector geometry.

Table 1: Ejector geometrical parameters.

\begin{tabular}{|l|l|l|}
\hline & Parameter & Value \\
\hline$D_{\text {PNT }}$ & Throat diameter & $6.12 \mathrm{~mm}$ \\
\hline$D_{\text {PNX }}$ & Primary nozzle exit diameter & $8.38 \mathrm{~mm}$ \\
\hline$D_{1 \text { in }}$ & Primary nozzle inlet diameter & $17.48 \mathrm{~mm}$ \\
\hline$D_{\text {PNW }}$ & Primary nozzle exterior diameter & $22.23 \mathrm{~mm}$ \\
\hline$L_{1 \text { conv }}$ & Length of the primary convergent & $32.16 \mathrm{~mm}$ \\
\hline$L_{1 \text { div }}$ & Length of the primary divergent & $9.88 \mathrm{~mm}$ \\
\hline$\delta$ & Half angle of the primary convergent & $10^{\circ}$ \\
\hline$\theta$ & Half angle of the primary divergent & $6.5^{\circ}$ \\
\hline$D_{\text {CAS }}$ & Diameter of the constant area section & $14.05 \mathrm{~mm}$ \\
\hline$D_{2 \text { in }}$ & Diameter of the secondary convergent & $52.30 \mathrm{~mm}$ \\
\hline$D_{2 \text { out }}$ & Exit diameter of the diffuser & $50.80 \mathrm{~mm}$ \\
\hline$L_{2 \text { conv }}$ & Length of the secondary convergent & $75.36 \mathrm{~mm}$ \\
\hline$L_{\text {CAS }}$ & Length of the constant area section & $77.09 \mathrm{~mm}$ \\
\hline$L_{2 \text { div }}$ & Length of the diffuser & $338.28 \mathrm{~mm}$ \\
\hline$\alpha$ & Half angle of the secondary convergent & $14.2^{\circ}$ \\
\hline$\beta$ & Half angle of the diffuser & $3.1^{\circ}$ \\
\hline
\end{tabular}

\subsection{Turbulence model and numerical settings}

The conservation equations of mass, total energy and momentum for a compressible fluid are solved using the finite volume method. The flow is assumed to be $2 \mathrm{D}$ axisymmetric and steady state. Advective and diffusive terms are discretized using, respectively, second-order upwind and second-order central difference schemes. The least square based method is used to approximate all gradients. The Coupled scheme is used to overcome the pressure-velocity coupling. Density based solvers are typically better suited in highly compressible flows. However, the pressure-based algorithm has shown to be able to handle ejector flows with shock-waves [26]-[28], while avoiding stability issues. High-order term relaxation is enabled to facilitate convergence. The NIST REFPROP equation database is used to determine the fluid thermodynamic and transport properties. For R245fa, these stem from the Helmholtz Free Energy equation of state [29]. The two-equation shear stress 
transport (SST) k- $w$ of Menter [15] is used throughout the study. Other two-equation models were not considered based on former benchmarks [10], [14].

As dictated by the EHDRC, the inlet and outlet conditions of the ejector correspond to overheated vapour. The inlet and outlet temperatures and pressures are provided by data collected by CanmetENERGY-Varennes on the experimental test bench described in Poirier et al. [30]. The primary temperature and pressure are those of the ejector primary inlet. The secondary inlet conditions are equal to the evaporator exit conditions. The outlet pressure and temperature are fed into a heat exchanger (regenerator) to pre-heat the high-pressure secondary liquid flow coming from the refrigerant pump. The additional heat supplied by the regenerator is a function of heat extracted from the regenerator. The mesh is created with CENTAUR v14.1.1. and is composed of 13 prismatic layers followed by varying triangles. Geometrical sources in the NXP section and in the diffuser provide additional refinements to the CAD sources and are seen in Figure 3. Each case studied has roughly $1.9 \times 10^{6}$ elements. This mesh allows for a $\mathrm{y}^{+}<5$ throughout the ejector. Iterations are performed for each case until convergence is reached when all residuals are well below $10^{-6}$. In order to properly access the effect of changing the turbulence model, constant geometry and operating conditions are used. The operating conditions used in the current work are presented in Table 2. All the computations were done on a workstation with $16 \mathrm{~GB}$ of RAM and an $8 \mathrm{core} 3.40 \mathrm{GHz}$ CPU. The average total calculation is 16 hours using 8 processors.

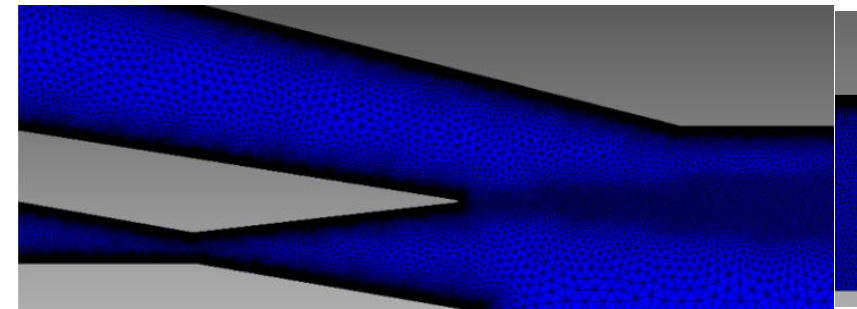

(a)

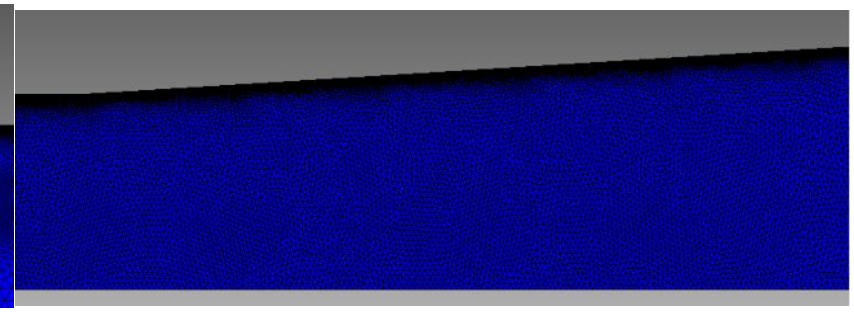

(b)

Figure 3: Mesh refinements: (a) from the primary nozzle to the middle of the CAS and (b) in the diffuser.

Table 2 : Ejector operating conditions.

\begin{tabular}{|l|l|l|l|l|l|}
\hline Operating condition & OP1 & OP2 & OP3 & OP4 & OP5 \\
\hline $\mathrm{A}_{\mathrm{t}}$ Throat area $\left(\mathrm{mm}^{2}\right)$ & $0.61 \mathrm{~A}_{\mathrm{t}}$ & $0.61 \mathrm{~A}_{\mathrm{t}}$ & $0.61 \mathrm{~A}_{\mathrm{t}}$ & $1.00 \mathrm{~A}_{\mathrm{t}}$ & $1.00 \mathrm{~A}_{\mathrm{t}}$ \\
\hline $\mathrm{P}_{1}$ Primary inlet pressure $(\mathrm{kPa})$ & 1570 & 1570 & 1570 & 1570 & 1570 \\
\hline $\mathrm{T}_{1}$ Primary inlet temperature $\left({ }^{\circ} \mathrm{C}\right)$ & 114.4 & 114.4 & 114.4 & 114.4 & 114.4 \\
\hline $\mathrm{P}_{2}$ Secondary inlet pressure $(\mathrm{kPa})$ & 160 & 160 & 160 & 160 & 160 \\
\hline $\mathrm{T}_{2}$ Secondary inlet temperature $\left({ }^{\circ} \mathrm{C}\right)$ & 31.5 & 41.7 & 41.4 & 49.6 & 45.2 \\
\hline $\mathrm{P}_{\text {out }}$ Outlet pressure $(\mathrm{kPa})$ & 260.0 & 309.9 & 355.3 & 420.1 & 400.8 \\
\hline $\mathrm{T}_{\text {out }}$ Outlet temperature $\left({ }^{\circ} \mathrm{C}\right)$ & 72.7 & 76.5 & 85.9 & 87.3 & 86.0 \\
\hline
\end{tabular}

\section{Results}

The two evaporator pressures chosen are function of the operational limits of the test bench in order to avoid operating below the ambient pressure. The effect of the needle within the VGE is also considered. The Mach number contours are studied in subsection 3.1. Then, the entrainment ratio, which is the defined as $\omega=\dot{m}_{2} / \dot{m}_{1}$ is evaluated for different needle positions using both CFD and experimental results. The effect of the needle is then compared to a primary pressure reduction.

\subsection{Performance for variable throat area $A_{t}$}

In order to establish the impact of the needle on the ejector performance, three different values of the primary nozzle throat area are tested: $1.00 \mathrm{At}, 0.80 \mathrm{At}$ and $0.61 \mathrm{At}$. The generator is operated at the higher limit of the test bench, which corresponds to a pressure $\mathrm{P} 1=1570 \mathrm{kPa}$. At 0.61 At the throat is obstructed by the cylindrical section before the needle tip. 1.00At corresponds to the needle being positioned $15 \mathrm{~mm}$ before the primary nozzle throat. The experimental tests were done for P2=160 kPa and P2=195 kPa. The NXP values correspond to the optimal NXP values of the experimental ejector, which are different for each test. Indeed, at the beginning of each experimental test, the NXP is adjusted until the highest value of 
$\dot{m}_{2}$ is obtained. This step is repeated for each different needle position and for both values of P2. The CFD points are calculated using a fixed primary inlet pressure of $1570 \mathrm{kPa}$, a primary inlet temperature of $114.5^{\circ} \mathrm{C}$ and a secondary inlet pressure of $160 \mathrm{kPa}$ and $195 \mathrm{kPa}$.

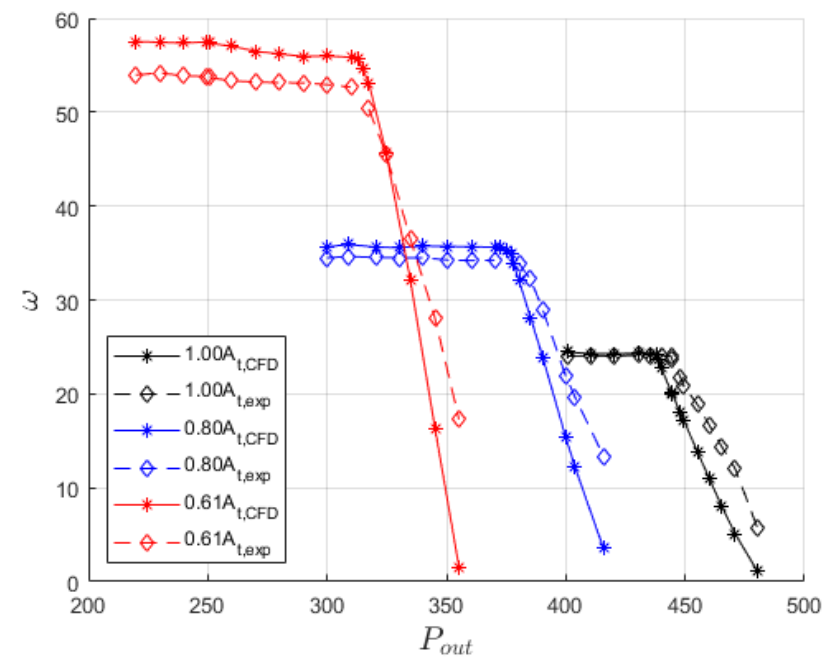

(a)

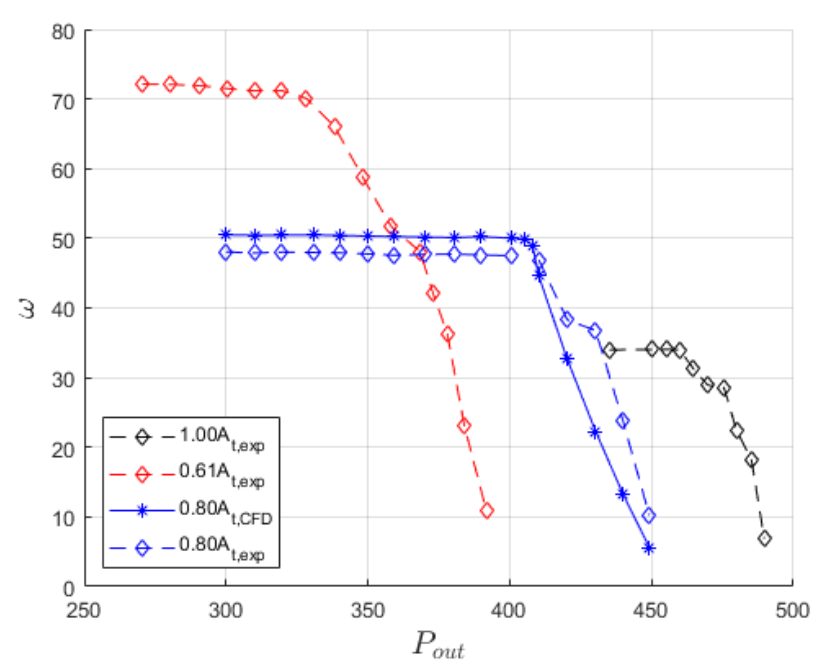

(b)

Figure 4: Entrainment ratio $(\omega)$ as a function of the outlet pressure $\left(\mathrm{P}_{\text {out }}\right)$ for $(\mathrm{a}) \mathrm{P}_{2}=160 \mathrm{kPa}$ with $0.61 \mathrm{~A}_{t}, 0.80 \mathrm{~A}_{t}$ and $1.00 \mathrm{~A}_{t}$ and (b) $\mathrm{P}_{2}=195 \mathrm{kPa}$ with $0.61 \mathrm{~A}_{\mathrm{t}}, 0.80 \mathrm{~A}_{\mathrm{t}}$ and $1.00 \mathrm{~A}_{\mathrm{t}}$. Comparison between $\mathrm{CFD}$ and experimental results.

The variation of $\mathrm{P}_{2}$ allows to see the effect of the needle for different sets of inlet conditions. A comparison of the entrainment ratio $(\omega)$ as a function of the outlet pressure $\left(\mathrm{P}_{\text {out }}\right)$ for $1.00 \mathrm{~A}_{\mathrm{t}}, 0.80 \mathrm{~A}_{\mathrm{t}}$ and $0.61 \mathrm{~A}_{t}$ at $\mathrm{P}_{2}=160 \mathrm{kPa}$ is displayed in Figure $4 \mathrm{a}$. A comparison of the entrainment ratio $(\omega)$ as a function of the outlet pressure $\left(\mathrm{P}_{\text {out }}\right)$ for $1.00 \mathrm{~A}_{t}, 0.80 \mathrm{~A}_{t}$ and $0.61 \mathrm{~A}_{t}$ at $\mathrm{P}_{2}=195 \mathrm{kPa}$ is seen in Figure $4 \mathrm{~b}$. The previous performance curves indicate that the CFD model is in good agreement with the experimental results. The CFD model over-predicts the performance of the ejector before the critical point and underpredicts the performance beyond the critical point. For example, at $\mathrm{P}_{2}=160 \mathrm{kPa}$ for $0.61 \mathrm{~A}_{\mathrm{t}}$, the error between both experimental and CFD entrainment ratio values is close to $6.5 \%$ while it reaches over $-90 \%$ on the last point of the off-design section. The good agreement between experimental and CFD data on the on-design condition is deemed more important than that of the off-design condition. The reduction of the throat area leads to an increase in the entrainment ratio and a decrease of the critical outlet pressure. The optimal NXP position changes with the needle position. The optimal NXP decreases with the increase in throat area reduction. Looking at the experimental results, for $\mathrm{P}_{2}=160 \mathrm{kPa}$, it goes from $\omega=24.1 \%$ and $\mathrm{P}_{\text {crit }}$ $=435.4 \mathrm{kPa}$ at $1.00 \mathrm{~A}_{\mathrm{t}}$ to $\omega=52.7 \%$ and $\mathrm{P}_{\text {crit }}=309.9 \mathrm{kPa}$ at $0.61 \mathrm{~A}_{\mathrm{t}}$. A similar increase is observed for a secondary inlet pressure of $195 \mathrm{kPa}$ with $\omega=34.0 \%$ and $\mathrm{P}_{\text {crit }}=459.9 \mathrm{kPa}$ and $\omega=71.2 \%$ and $\mathrm{P}_{\text {crit }}=319.7 \mathrm{kPa}$ for $1.00 \mathrm{~A}_{\mathrm{t}}$ and $0.61 \mathrm{~A}_{\mathrm{t}}$ respectively. The entrainment ratio is higher for all cases at $195 \mathrm{kPa}$. The reduction of the throat area leads to a reduction of the critical $\mathrm{C}_{R}$ since $\mathrm{P}_{2}$ is fixed and $\mathrm{P}_{\text {crit }}$ decreases. In order to properly access the effect of the needle position on ejector performance, it is important to compare different needle positions at the same operating conditions. A test is done at the operating conditions of OP2 but for throat area values of $0.61 \mathrm{~A}_{\mathrm{t}}$ and $0.80 \mathrm{~A}_{\mathrm{t}}$. Another test is done at the operating conditions of OP5 but for both $0.80 \mathrm{~A}_{\mathrm{t}}$ and $1.00 \mathrm{~A}_{\mathrm{t}}$. The Mach contours are traced for each considered case.

Figure 5 displays the Mach contours for both $0.80 \mathrm{~A}_{t}$ and $0.61 \mathrm{~A}_{t}$ at $\mathrm{OP} 2$ (a) as well as the Mach contours for $1.00 \mathrm{~A}_{t}$ and $0.80 \mathrm{~A}_{\mathrm{t}}$ at $\mathrm{OP} 5(\mathrm{~b})$. At OP2, the primary mass flow rate drops from $159.7 \mathrm{~g} \cdot \mathrm{s}^{-1}$ at $0.80 \mathrm{~A}_{\mathrm{t}}$ to $119.6 \mathrm{~g} \cdot \mathrm{s}^{-1}$ at $0.61 \mathrm{~A}_{\mathrm{t}}$. This decrease in the primary mass flow rate leads to an increase of the secondary mass flow rate from $57.32 \mathrm{~g} \cdot \mathrm{s}^{-1}$ to $66.81 \mathrm{~g} \cdot \mathrm{s}^{-1}$. The Mach contours indicate that, for the same operating conditions, having the needle pushed further into the primary nozzle throat reduces the primary jet core size and strength. This phenomenon is also seen by comparing $0.80 \mathrm{~A}_{t}$ and $1.00 \mathrm{~A}_{t}$ at $\mathrm{OP} 5$. At $\mathrm{OP}$, for $0.80 \mathrm{~A}_{t}$, the ejector works under on-design conditions versus OP5, which shows the off-design performance. The shock train tail leads further into the diffuser for the higher throat area value. 


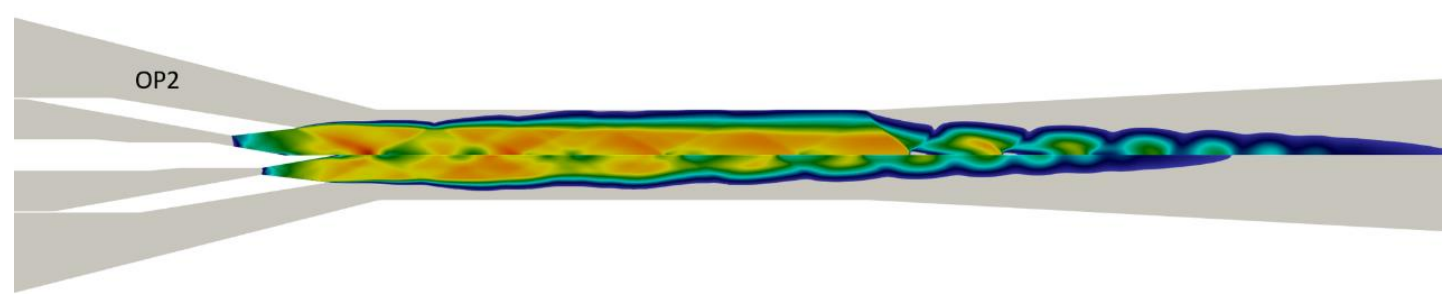

(a)

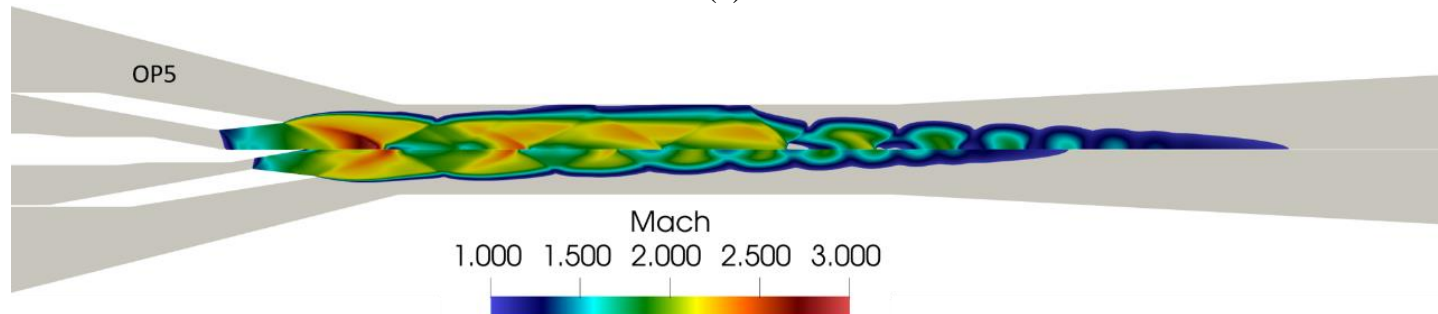

(b)

Figure 5: Mach contours at (a) OP2 for $0.80 \mathrm{~A}_{t}$ and $0.61 \mathrm{~A}_{t}$ and at (b) OP5 for $1.00 \mathrm{~A}_{t}$ and $0.80 \mathrm{~A}_{t}$.

Figure 5 clearly illustrates that pushing the needle further into the primary nozzle throat reduces the primary jet size, which allows for a greater entrained quantity of secondary mass flow. At the critical point, the reduction of the secondary mass flow rate leads to an increase of the space occupied by the high-pressure jet core. The reduction of the throat area is proportional to the reduction of the primary mass flow rate. A $30 \%$ reduction in $\mathrm{A}_{t}$ leads to a $30 \%$ reduction in $\dot{m}_{1}$. However, the secondary mass flow rate increases with the reduction of the throat area. Operating at the maximum primary pressure, the use of the needle for a maximum reduction increases the quantity of cooling that can be produced. The use of a needle provides a similar effect on the primary mass flow rate as changing the primary inlet pressure. By reducing the primary inlet pressure, the primary mass flow rate also drops. In order to capture this phenomenon, different primary pressure values have been tested experimentally. Table 3 presents different tested values of $\mathrm{P}_{1}$. For an ejector without a needle, experimental primary pressure values of $1265 \mathrm{kPa}$ and $1006 \mathrm{kPa}$ are tested. For $1006 \mathrm{kPa}$, the corresponding critical outlet pressure $\mathrm{P}_{\text {crit }}=312 \mathrm{kPa}$ which is the same as that of an ejector with $\mathrm{P}_{1}=1570 \mathrm{kPa}$ and $0.61 \mathrm{~A}_{\mathrm{t}}$. The primary mass flow rate $\dot{m}_{1}$ at 1006 $\mathrm{kPa}$ is slightly higher at $125.5 \mathrm{~g} \cdot \mathrm{s}^{-1}$ compared to $122.1 \mathrm{~g} \cdot \mathrm{s}^{-1}$ for $0.61 \mathrm{~A}_{\mathrm{t}}$ and $\dot{m}_{2}$ is slightly lower at $59.0 \mathrm{~g} \cdot \mathrm{s}^{-1}$ compared to 64.3 $\mathrm{g} \cdot \mathrm{s}^{-1}$. The same trend is observed at $\mathrm{P}_{1}=1265 \mathrm{kPa}$ with $\dot{m}_{1}=158.0 \mathrm{~g} \cdot \mathrm{s}^{-1}$ and $\dot{m}_{2}=55.2 \mathrm{~g} \cdot \mathrm{s}^{-1}$ which corresponds to an entrainment ratio of $33 \%$. This is comparable to a throat area of $0.80 \mathrm{~A}_{t}$ at $\mathrm{P}_{1}=1570 \mathrm{kPa}$ with a slightly better entrainment ratio value of $34.3 \%$. This analysis allows to establish that variable secondary flow rate values can be obtained by modulating the primary pressure instead of using a needle to control the primary throat area. Similar ejector performances are seen through the comparison of these tests.

Table 3: Experimental tests for different values of $\mathrm{P}_{1}$.

\begin{tabular}{|l|c|c|c|c|c|c|c|}
\hline \multirow{2}{*}{ Throat } & $\mathrm{P}_{1}$ & $\mathrm{P}_{2}$ & $\dot{m}_{1}$ & $\dot{m}_{2}$ & $\omega$ & $\mathrm{P}_{\text {crit }}$ & NXP \\
\cline { 2 - 8 } & $(\mathrm{kPa})$ & $(\mathrm{kPa})$ & $\left(\mathrm{g} \cdot \mathrm{s}^{-1}\right)$ & $\left(\mathrm{g} \cdot \mathrm{s}^{-1}\right)$ & $(\%)$ & $(\mathrm{kPa})$ & $(\mathrm{mm})$ \\
\hline No needle & 1570 & 160 & 200.3 & 48.4 & 24.1 & 444 & 18.1 \\
\hline No needle & 1265 & 160 & 158 & 52.1 & 33 & 372 & 13.2 \\
\hline No needle & 1006 & 160 & 125.5 & 59 & 47 & 312 & 8.5 \\
\hline $0.61 \mathrm{~A}_{\mathrm{t}}$ & 1570 & 160 & 122.1 & 64.3 & 52.7 & 312 & 8.3 \\
\hline $0.81 \mathrm{~A}_{\mathrm{t}}$ & 1570 & 160 & 161.1 & 55.2 & 34.3 & 379 & 12.9 \\
\hline
\end{tabular}

\section{Conclusion}

The current study has explored both numerically and experimentally the effect of the needle on the performance of a variable geometry ejector. The objectives have been achieved with regards to observing the effect of the needle as a variable 
power control device within the ejector. The numerical results allowed to observe local flow phenomena caused by modulating the needle position. The main results could be summarized as follows:

- The needle can be used to modulate the primary mass flow rate. The variable geometry ejector does expand the operating range of ejector heat driven refrigeration cycles without incurring significant material or electricity costs. However, attention should be given on how to properly control the needle in a commercial system. At a fixed value of $\mathrm{P}_{2}$, the reduction of the throat area leads to a reduction of the critical outlet pressure $\mathrm{P}_{\text {out }}$.

- The needle tip geometry should be considered for accurate capacity control in order to maximize the throat area reduction.

- In later studies, parallel ejectors and pulse width modulation in single phase ejector heat driven refrigeration cycles should be more deeply studied to evaluate their potential use as variable power systems.

\section{Acknowledgements}

The authors acknowledge the support of the NSERC chair on industrial energy efficiency established in 2019 at Université de Sherbrooke funded by Hydro-Québec, Natural Resources Canada (CanmetEnergy-Varennes) and Emerson Canada. Computational resources have been provided by Compute Canada.

\section{References}

[1] G. Besagni, Ejectors on the cutting edge: The past, the present and the perspective, Energy, vol. 170, p. 998-1003, 2019.

[2] G. Grazzini, A. Milazzo, and F. Mazzelli, Ejectors for Efficient Refrigeration: Design, Applications and Computational Fluid Dynamics. Springer, 2018.

[3] X. Ma, W. Zhang, S. A. Omer, and S. B. Riffat, Experimental investigation of a novel steam ejector refrigerator suitable for solar energy applications, Appl. Therm. Eng., vol. 30, nº 11, p. 1320-1325, 2010.

[4] J. Yu, H. Chen, Y. Ren, and Y. Li, A new ejector refrigeration system with an additional jet pump, Appl. Therm. Eng., vol. 26, n ${ }^{\circ}$ 2, p. 312-319, 2006.

[5] K. O. Shestopalov, B. J. Huang, V. O. Petrenko, and O. S. Volovyk, Investigation of an experimental ejector refrigeration machine operating with refrigerant R245fa at design and off-design working conditions. Part 2. Theoretical and experimental results, Int. J. Refrig., vol. 55, p. 212-223, 2015.

[6] Y. Fang, S. Croquer, S. Poncet, Z. Aidoun, and Y. Bartosiewicz, Drop-in replacement in a R134 ejector refrigeration cycle by HFO refrigerants, Int. J. Refrig., vol. 77, p. 87-98, 2017.

[7] Z. Aidoun, K. Ameur, M. Falsafioon, and M. Badache, Current Advances in Ejector Modeling, Experimentation and Applications for Refrigeration and Heat Pumps. Part 1: Single-Phase Ejectors, Inventions, vol. 4, $\mathrm{n}^{\circ}$ 1, Art. $\mathrm{n}^{\circ}$ 1, 2019.

[8] B. J. Huang and J. M. Chang, Empirical correlation for ejector design, Int. J. Refrig., vol. 22, nº 5, p. 379-388, 1999.

[9] I. W. Eames, A new prescription for the design of supersonic jet-pumps: the constant rate of momentum change method, Appl. Therm. Eng., vol. 22, n ${ }^{\circ}$ 2, p. 121-131, 2002.

[10] Y. Bartosiewicz, Z. Aidoun, P. Desevaux, and Y. Mercadier, Numerical and experimental investigations on supersonic ejectors, Int. J. Heat Fluid Flow, vol. 26, nº 1, p. 56-70, 2005.

[11] T. Sriveerakul, S. Aphornratana, and K. Chunnanond, Performance prediction of steam ejector using computational fluid dynamics: Part 2. Flow structure of a steam ejector influenced by operating pressures and geometries, Int. J. Therm. Sci., vol. 46, no 8, p. 823-833, 2007.

[12] N. Ruangtrakoon, T. Thongtip, S. Aphornratana, and T. Sriveerakul, CFD simulation on the effect of primary nozzle geometries for a steam ejector in refrigeration cycle, Int. J. Therm. Sci., vol. 63, p. 133-145, 2013.

[13] J. Gagan, K. Smierciew, D. Butrymowicz, and J. Karwacki, Comparative study of turbulence models in application to gas ejectors, Int. J. Therm. Sci., vol. 78, p. 9-15, 2014.

[14] S. Croquer, S. Poncet, and Z. Aidoun, Turbulence modeling of a single-phase R134a supersonic ejector. Part 1: Numerical benchmark, Int. J. Refrig., vol. 61, p. 140-152, 2016.

[15] F. R. Menter, Two-equation eddy-viscosity turbulence models for engineering applications, AIAA J., vol. 32, $\mathrm{n}^{\circ} 8$, p. 1598-1605, 1994.

[16] F. Mazzelli and A. Milazzo, Performance analysis of a supersonic ejector cycle working with R245fa, Int. J. Refrig., vol. 49, p. 79-92, 2015. 
[17] P. Gullo, M. R. Kærn, M. Haida, J. Smolka, and S. Elbel, A review on current status of capacity control techniques for two-phase ejectors, Int. J. Refrig., vol. 119, p. 64-79, 2020.

[18] J. Smolka, Z. Bulinski, A. Fic, A. J. Nowak, K. Banasiak, and A. Hafner, A computational model of a transcritical R744 ejector based on a homogeneous real fluid approach, Appl. Math. Model., vol. 37, nº 3, p. 1208-1224, 2013.

[19] M. Sokolov and D. Hershgal, Enhanced ejector refrigeration cycles powered by low grade heat. Part 1. Systems characterization, Int. J. Refrig., vol. 13, nº 6, p. 351-356, 1990.

[20] P. Gullo, M. Birkelund, E. E. Kriezi, and M. Ryhl Kærn, Novel flow modulation method for R744 two-phase ejectors - Proof of concept, optimization and first experimental results, Energy Convers. Manag., vol. 237, p. 114082, 2021.

[21] D.-W. Sun, Variable geometry ejectors and their applications in ejector refrigeration systems, Energy, vol. 21, $\mathrm{n}^{\mathrm{o}} 10$, p. 919-929, 1996.

[22] Z. Chen, X. Jin, C. Dang, and E. Hihara, Ejector performance analysis under overall operating conditions considering adjustable nozzle structure, Int. J. Refrig., vol. 84, p. 274-286, 2017.

[23] S. Varga, A. C. Oliveira, X. Ma, S. A. Omer, W. Zhang, and S. B. Riffat, Experimental and numerical analysis of a variable area ratio steam ejector, Int. J. Refrig., vol. 34, nº 7, p. 1668-1675, 2011.

[24] W. Fu, Z. Liu, Y. Li, H. Wu, and Y. Tang, Numerical study for the influences of primary steam nozzle distance and mixing chamber throat diameter on steam ejector performance, Int. J. Therm. Sci., vol. 132, p. 509-516, 2018.

[25] B. Shahzamanian, S. Varga, J. Soares, A. I. Palmero-Marrero, and A. C. Oliveira, Performance evaluation of a variable geometry ejector applied in a multi-effect thermal vapor compression desalination system, Appl. Therm. Eng., vol. 195, p. 117177, 2021.

[26] C. Li and Y. Z. Li, Investigation of entrainment behavior and characteristics of gas-liquid ejectors based on CFD simulation, Chem. Eng. Sci., vol. 66, nº 3, p. 405-416, 2011.

[27] Y.Zhu and P. Jiang, Experimental and numerical investigation of the effect of shock wave characteristics on the ejector performance, Int. J. Refrig., vol. 40, p. 31-42, 2014.

[28] S. Croquer, S. Poncet, and N. Galanis, Comparison of ejector predicted performance by thermodynamic and CFD models, Int. J. Refrig., vol. 68, p. 28-36, 2016.

[29] E. W. Lemmon and R. Span, Short Fundamental Equations of State for 20 Industrial Fluids, J. Chem. Eng. Data, vol. $51, \mathrm{n}^{\mathrm{o}} 3$, p. 785-850, 2006.

[30] M. Poirier, D. Giguère and H. Sapoundjiev, Experimental parametric investigation of vapor ejector for refrigeration applications, Energy, vol. 162, pp. 1287-1300, 2018. 